pounds are expended annually on the maintenance of residential institutions for treatment. During twenty years of anti-tuberculosis campaign, the decline in the mortality from the disease has been striking-from a total of 53,120 deaths in 1911 to 35,745 in 1930 . One of the most interesting and important sections of this Report deals with the results of sanatorium treatment. This is very difficult to evaluate, for the ultimate result depends so much on a variety of factors, such as (1) the type of the disease-some cases progress to a fatal issue in spite of all treatment, (2) the social position and sex of the patients, (3) the stage of the disease when treatment is commenced, (4) the age of the patients-pulmonary tuberculosis in the young adult tends to shorten life much more markedly than when it occurs in or after middle life, (5) the circumstances of the patient after discharge-the character of his home surroundings, his own care of his health, the nature of his occupation, and the like. It is concluded that some fifty-seven per cent of male and sixty-seven per cent of female patients in the second stage of pulmonary tuberculosis survive, often with good working capacity, for five years or more ; a result which fully justifies the provision of sanatorium treatment Much important information is embodied in this Report upon such subjects as after-care and village settlements for the tuberculous, methods of diagnosis, and special forms of medical and surgical treatment.

\section{Science in the 'Sixties}

A pamphlet with this title by Sir Oliver Lodge forms one of a series edited by Mr. John Drinkwater and addressed to men of letters. In it Sir Oliver contrasts the indifference displayed by the public and the Press to scientific discoveries made in the 'sixties with the universal interest shown at the present time in such subjects as relativity and the constitution of the stars. For the science of the 'sixties, Sir Oliver confines himself almost entirely to the theory of the electromagnetic field brought forward by Maxwell as the mathematical interpretation of Faraday's lines of force. He uses the words 'juggled with' to describe the process by which Maxwell evolved the electromagnetic theory of light from his mathematical expressions. This seems to us an unfortunate choice of words, likely to produce a wrong impression on the minds of readers. The steady progress from Maxwell to present-day wireless is outlined, and Sir Oliver concludes by giving his opinions on current theories. The new doctrine of uncertainty he summarises in " the act of observing carries with it inevitably an act of perturbing", but he denies that this renders events unpredictable. By 'faith' only does he accept relativity, but wave mechanics "is a healthy infant of great promise"

\section{Scientific Apparatus of Historical Importance}

SEvEraL daily newspapers recently published a letter from the Institute of Physics over the signatures of Lord Rutherford and others asking for the co-operation of anyone possessing pieces of apparatus likely to be of historical importance. In 1925 the Institute of Physics appointed a committee to advise on the preservation of such apparatus. This committee is anxious to trace any pieces with which fundamental research in physical science has been carried out, and to arrange for their preservation. The committee has also entered upon the task of drawing up a catalogue of such pieces. Several pieces of great historical importance have already been secured for the nation and are now housed in the Science Museum at South Kensington, and the response to the recent letter has brought to light several other important pieces. Articles describing and cataloguing such pieces are published from time to time in the Journal of Scientific Instruments. Many readers of NATURE may have such apparatus in their possession or under their charge; and the Secretary of the Institute of Physies, 1 Lowther Gardens, Exhibition Road, London, S.W.7, will be grateful for any information that will assist in tracing such pieces or in completing the catalogue. For the benefit of future historians of physical science it is desirable to have as complete a record as is possible of the work of British physicists, and it is to this end that this task has been undertaken.

\section{Cremation and Population}

Mrs. Alec-Tweenie's address on "Cremation the World Over" at the Cremation Conference, which was held at Brighton on July 18-21, reinforced a strong appeal for the wider adoption of this method of disposal of the dead by reference to the distribution of the custom of burning the dead among peoples of antiquity and non-European races. She dwelt in particular on the practice of cremation among the Hindus, contrasting it in detail with the methods of burial among the Chinese, and pointing out how among the latter reverence for the last resting-places of the dead, where land enclosing burial mounds is under cultivation, hampers agriculture and is an increasing menace to food supply among a teeming population which already produces barely enough for its needs. The vastness of the population, it might be added, makes the practice increasingly detrimental from the point of view of hygiene. Although Mrs, Tweedie did not hesitate to make use of the appeal to the emotion which reflection on the conditions and consequences of inhumation never fails to arouse, a marked feature of her address was the emphasis with which she stressed the import of cremation as a factor in the world's population problem, linking it up with food supply and birth control in relation to over-population. As she put it in her closing words, "Without birth control and world cremation, what will the end be?" Mrs. Alec-Tweedie was the first and only woman on the council of the Cremation Society of England for more than ten years. She is the daughter of the late Dr. George Harley, F.R.S., of Harley Street, and her brother was Dr. Vaughan Harley. Her brother-inlaw is Dr. Francis Goodbody, who has done much work for the centenary meeting of the British Medical Association.

\section{Population of London}

THE volume of the Census, 1931, which covers the County of London has been published (London: H.M. Stationery Office, $3 s$. net). The total population enumerated in the City of London and the twenty- 